\title{
TRANSFER PENGETAHUAN PEMBUATAN PEMBANGKIT LISTRIK TENAGA PIKOHIDRO UNTUK PENERANGAN JALAN
}

\author{
KNOWLEDGE TRANSFER FOR MAKING PYCOHIDRO POWER PLANT \\ FOR ROAD LAMPS
}

\author{
${ }^{1)}$ Hari Prasetijo, ${ }^{2)}$ Widhiatmoko H.P, ${ }^{3)}$ P. Setyo Nugroho \\ ${ }^{1,2,3)}$ Fakultas Teknik, Universitas Jenderal Soedirman \\ email : hariprasetijo73@gmail.com
}

\begin{abstract}
ABSTRAK
Dusun Siwarak Kulon berbatasan dengan hutan pinus seluas 1.014,4 ha asset Perum Perhutani Kesatuan Pemangkuan Hutan (KPH) Banyumas Timur dengan ketinggian 200 - $250 \mathrm{Mdpl}$. Jalan beraspal hanya jalan utama, sedangkan akses lain berupa jalan maka dan belum dilengkapi penerangan jalan umum. Di kawasan ini terdapat sungai Curug yang memiliki terjunan setinggi 1,2 meter. Tujuan dari kegiatan ini adalah melakukan transfer pengetahuan melalui pendampingan pembuatan pembangkit listrik tenaga pikohidro untuk penerangan jalan di RT 02 dan RT 03 RW 03 dusun Siwarak desa Watuagung kecamatan Tambak yang terletak pada ketinggian 200-250 Mdpl pada kawasan hutan Perum Perhutani Banyumas Timur. Pencapaian tujuan program ini dilakukan dengan metode pengukuran potensi daya dari aliran sungai dan parameter listrik, analisis kapasitas daya generator, pembuatan bendung,pembuatan penstock dan turbin, pemasangan penstock dan turbingenerator, membuat penerangan jalan umum serta transfer pengetahuan melalui diskusi sistem pembangkit listrik tenaga piko hidro dan lampu LED gun pembangkit listrik tenaga pikohidro dengan kapasitas 1000 watt, dibangun penpenghematan energi listrik penerangan. Hasil yang dicapai dari kegiatan ini adalah : dibanerangan jalan umum, serta mendapatkan 2 warga yang memiliki kemampuan perawatan pembangkit listrik untuk memastikan keberlanjutan sistem tersebut.
\end{abstract}

Kata kunci : Transfer, Pengetahuan, Pikohidro, Penerangan, LED

\begin{abstract}
Siwarak Kulon village is bordered by pine forest covering an area of 1,014.4 ha of Perhutani's Perum Forest Rehabilitation Unit (KPH) of East Banyumas with an altitude of 200-250 masl. Paved roads are only the main road, while other access in the form of macadam roads has not been equipped with public street lighting. In this area there is the Curug river which has a 1.2 meter high waterfall. The purpose of this activity is to transfer knowledge through the assistance of making picohydro power plant for street lighting in RT 02 and RT 03 RW 03 Siwarak hamlet of Watuagung village, Tambak subdistrict, located at an altitude of 200-250 Mdpl on forest area of Perum Perhutani Banyumas Timur. The achievement of the objectives of the program is carried out by:measuring the power potential of river flow and electrical parameters, generator power capacity analysis, making weirs, build penstock and making turbine, mounting, penstock and turbine generator, create public road lighting as well as, knowledge transfer through discussions of hydropower power systems and LED lighting power saving lighting. The results of this activity are: built 1000-watt pikohidro power plant, built public street lighting, and get 2 residents who have power plant maintenance capability to ensure the sustainability of the system.
\end{abstract}

Keywords: Transfer, Knowledge, Picohydro, LED 


\section{PENDAHULUAN}

Dusun Siwarak desa Watuagung Kecamatan Tambak Kabupaten Banyumas Provinsi Jawa Tengah terletak pada 70 34'4.77' Lintang Selatan dan $109^{0} 24$ '51,70" Bujur Timur. Sebagian wilayah di RT 02 RW 03 berbatasan dengan hutan pinus aset Perum Perhutani Kesatuan Pemangkuan Hutan (KPH) BanyumasTimur dengan ketinggian $200-$ 250 Mdpl. Secara umum Dusun Siwarak jauh dan cukup terpencil dari tempat aktivitas ekonomi maupun pendidikan karena terpisahkan oleh hutan pinus kearah pusat desa Watuagung. Pada wilayah ini mengalir sungai Curug dengan beberapa perbedaan elevasi (tinggi jatuh/head). Berdasar data dari Dinas ESDM Kabupaten Banyumas aliran sungai Curug memiliki potensi daya listrik sampai 9,85 $\mathrm{kW}$ seperti pada tabel 1. Dengan rata-rata hujan pertahun sebanyak 109 hari dengan curah rata-rata $2.897 \mathrm{~mm}$ pertahun maka sangat layak untuk pengembangan pembangkit listrik tenaga pikohidro (PLTPH). Menurut Akhmad (2008), pembangkit listrik tenaga pikohidro (PLTPH) merupakan system pembangkit listrik yang menggunakan sumber tenaga air dalam skala kecil dengan kapasitas dibawah $5 \mathrm{~kW}$.

Tabel 1. Potensi energi air untuk tenaga listrik

\begin{tabular}{|l|l|c|}
\hline No. & Sungai & Daya $(\mathbf{k W})$ \\
\hline 1 & Tajum & 38,76 \\
\hline 2 & PandakRaden & 10,83 \\
\hline 3 & Curug & 9,85 \\
\hline 4 & Kaliomas & 8,91 \\
\hline 5 & Banjaran II & 8,69 \\
\hline 6 & Logawa & 8,64 \\
\hline 7 & Banjaran I & 6,94 \\
\hline 8 & Kertadirjan & 6,91 \\
\hline 9 & Sokawera & 6,79 \\
\hline
\end{tabular}

Sumber : ESDM Kabupaten Banyumas, 2010

Berdasakan diskusi yang pernah dilakukan dengan masyarakat di RT 02 dan
RT 03 Dusun Siwarak, diperlukan penerangan jalan umum dengan memanfaatkan energy potensi air dan pengetahuan mengenai pembangkit listrik tenaga pikohidro.

Pada aliran sungai Curug di sekitar area hutan pinus milik Perum Perhutani terdapat terjunan dengan ketinggian sekitar 1,2 meter. Aliran sungai di lokasi tersebut kontinyu sepanjang tahun. Dari pengukuran awal debit sungai sekitar 0,1274 m3/detik. Dari perkiraan data tersebut maka perkiraan daya listrik dari potensi pembangkitan listrik sekitar 1000 watt atau $1 \mathrm{~kW}$.

Daya listrik ini menyuplai lampu Light Emitting Diode (LED) yang dipilih untuk PJU karena jenis lampu yang memiliki efisiensi tinggi. Penggunaan lampu LED yang merupakan teknologi terkini dalam penerangan akan menjadi sarana pembanding dan pembuktian dalam membantu sosialisasi salah satu cara penghematan energy listrik untuk penerangan. Lampu LED memiliki keunggulan dalam life time dan efisiensi energi di banding jenis lampu lain. Dibanding lampu TL, lampu LED memiliki luminasi $4 \mathrm{x}$ lebih baik dan life time 3x lebih lama (Faridah, 2018).

\section{METODE}

Pencapaian tujuan program ini dilakukan dengan tahapan pendampingan (1)pengukuran potensi daya dari aliran sungai dan parameter listrik (2) analisis kapasitas daya generator, (3) pembuatan bendung, (4) pembuatan penstock dan urbin (5) pemasangan penstock dan turbingenerator (6) membuat penerangan jalan umum serta (7) transfer pengetahuan melalui diskusi system pembangkit listrik tenaga pikohidro dan penghematan energy listrik penerangan. Indikator keberhasilan kegiatan ini adalah dibangunnya pembangkit listrik pikohidro bersama masyarakat untuk penerangan jalan sehingga masyarakat memiliki 
pengetahuan dalam mengelola operasionalnya.

\section{HASIL DAN PEMBAHASAN}

\section{Pengukuran Debit (Q)}

Untuk mengetahui debit aliran sungai harus diukur kecepatan aliran sungai (V) dan luas penampang sungai (A). Menurut Myson (2013), metode pengukuran kecepatan aliran sungai metode pelampung akan memberikan hasil yang baik jika dilakukan pada bagian sungai yang lurus dan tidak memiliki peruhahan lebar yang signifikan. Penulis menggunakan metode pelampung pada lintasan 6,8 yang dilakukan di lokasi hulu (I) dan hilir (II) dengan 3 data pada masing-masing lokasi sehingga diperoleh data seperti dalam tabel 2 .

Luas penampang sungai sebesar $0,336 \mathrm{~m}^{2}$ diperoleh dengan cara melakukan pengukuran kedalaman sungai pada 5 titik pada hulu dan hilir seperti pada gambar 1 .

Tabel 2. Kecepatan aliran sungai Curug

\begin{tabular}{|c|c|c|}
\hline \multicolumn{3}{|c|}{$\mathbf{V}(\mathbf{m} / \mathbf{s})$} \\
\hline $\begin{array}{c}\mathbf{V}_{\mathbf{1}(\mathbf{I})} \\
(\mathrm{t}=10.44 \mathrm{~s})\end{array}$ & $\begin{array}{c}\mathbf{V}_{\mathbf{2 ( I )}} \\
(\mathrm{t}=11 \mathrm{~s})\end{array}$ & $\begin{array}{c}\mathbf{V}_{\mathbf{3 ( I})} \\
(\mathrm{t}=12.9 \mathrm{~s})\end{array}$ \\
\hline $0.65 \mathrm{~m} / \mathrm{s}$ & $0.618 \mathrm{~m} / \mathrm{s}$ & $0.527 \mathrm{~m} / \mathrm{s}$ \\
\hline $\begin{array}{c}\mathbf{V}_{\mathbf{1}(\text { II) }} \\
(\mathrm{t}=31.83 \mathrm{~s})\end{array}$ & $\begin{array}{c}\mathbf{V}_{\mathbf{2}(\text { II) }} \\
(\mathrm{t}=28.19 \mathrm{~s})\end{array}$ & $\begin{array}{c}\mathbf{V}_{\mathbf{3}(\text { III })} \\
(\mathrm{t}=27.5 \mathrm{~s})\end{array}$ \\
\hline $0.214 \mathrm{~m} / \mathrm{s}$ & $0.241 \mathrm{~m} / \mathrm{s}$ & $0.247 \mathrm{~m} / \mathrm{s}$ \\
\hline
\end{tabular}

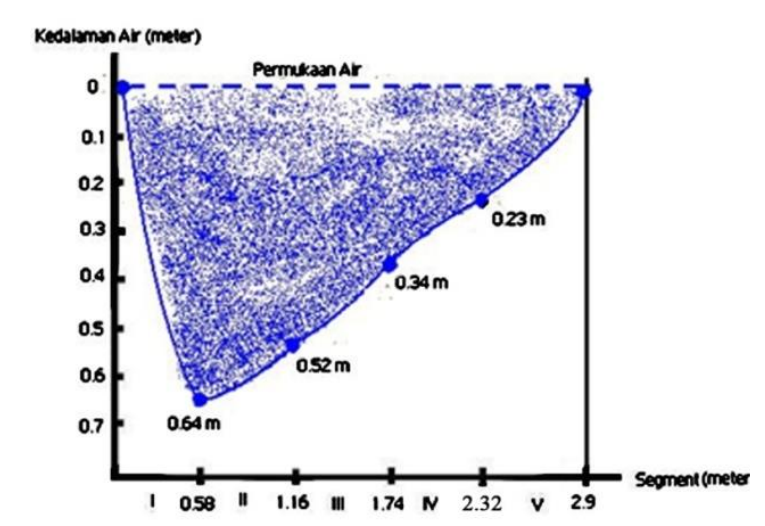

(a) Hulu

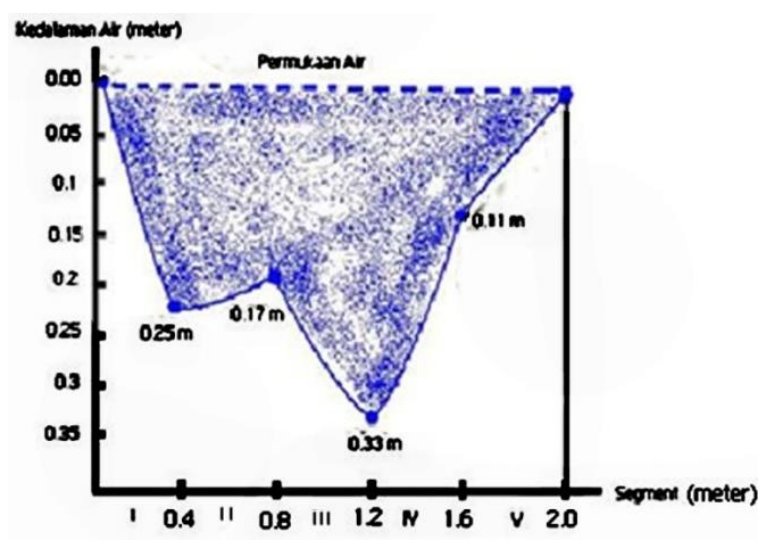

(b) Hilir

Gambar 1. Penampang sungai Curug

Maka besarnya debit (Q) untuk

- Penampang I

$$
\begin{aligned}
& Q_{\text {penampang } \boldsymbol{I}}=\boldsymbol{V} \cdot \boldsymbol{A} \\
& =\left(0.9^{*} \times 0.598 \mathrm{~m} / \mathrm{s}\right) \times 0.336 \mathrm{~m}^{2} \\
& =0.181 \mathrm{~m}^{3} / \mathrm{s}
\end{aligned}
$$

- Penampang II

$$
\begin{aligned}
& Q_{\text {penampang II }}=\boldsymbol{V} \cdot \boldsymbol{A} \\
& =\left(0.9^{*} \times 0.234 \mathrm{~m} / \mathrm{s}\right) \times 1.0034 \mathrm{~m}^{2} \\
& =0.211 \mathrm{~m}^{3} / \mathrm{s}
\end{aligned}
$$

Sehingga

$$
\begin{aligned}
Q_{\text {rata-rata }} & =\frac{Q_{\text {penampang I }}+Q_{\text {penampang II }}}{2} \\
& =\frac{0.181 \mathrm{~m}^{3} / \mathrm{s}+0.211 \mathrm{~m}^{3} / \mathrm{s}}{2} \\
& =0.196 \mathrm{~m}^{3} / \mathrm{s} \times 0.65^{* *}=0.1274
\end{aligned}
$$

$\mathrm{m}^{3} / \mathrm{s}$

*)faktor reduksi untuk pengukuran kecepatan air menggunakan metode apung, besarnya 0.9

**)faktor koreksi untuk jenis sungai

dangkal dan aliran bebas $\left(\mathrm{A}<10 \mathrm{~m}^{2}\right)$,

besarnya 0.65 (Kaigai, 2003)

\section{Pengukuran Head Efektif}

Pengukuran head efektif dapat diilustrasikan pada gambar dibawah ini. 


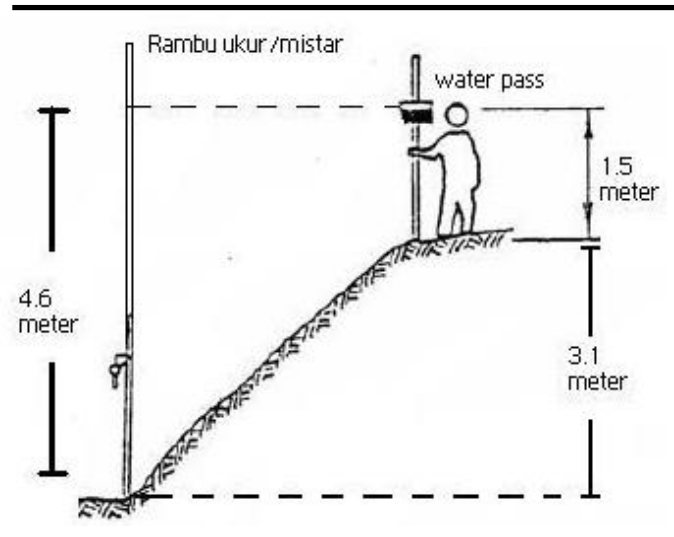

Gambar 2. Pengukuran Head efektif $\left(\mathrm{H}_{\mathrm{eff}}\right)$

Dari hasil pengukuran tersebut didapatkan nilai Head Efektif yaitu dengan menghitung tinggi yang di tembak thelidoit kerambu ukur (mistar) dikurangi tinggi dari tripod yang di jabarkan dengan perhitungan dibawah ini :

$$
\begin{aligned}
\text { Heff } & =\text { Hmistar }- \text { Htripod } \\
& =2,7 \text { meter }-1,5 \text { meter } \\
& =1,2 \text { meter }
\end{aligned}
$$

\section{Potensi Daya}

Berdasarkan pengukuran potensi debit rata-rata dan tinggi jatuh air efektif di aliran sungai curug, Siwarak, desa Watuagung, Kecamatan. Tambak, Banyumas. Di dapatkan nilai debit (Q) desain sebesar $0.1274 \mathrm{~m}^{3} / \mathrm{s}$ serta tinggi jatuh air 1.2 meter. Mengacu pada data tersebut maka daya $(\mathrm{kW})$ yang tersedia di aliran sungai curug dapat dihitung sbb :

Pin turbin $=\rho . g$. Heff.$Q$ desain $=1000 \mathrm{~kg} / \mathrm{m}^{3} \times 9.8 \mathrm{~m} / \mathrm{s}^{2} \times 1,2 \mathrm{~m} \times 0.1274$ $\mathrm{m}^{3} / \mathrm{s}$

$=1.498 \mathrm{Watt}$

$=1,498 \mathrm{~kW}$

\section{Daya keluaran generator}

Dengan efesiensi generator sekitar $70 \%$ maka daya keluaran generator pada saat debit $0.1274 \mathrm{~m} 3 / \mathrm{s}$ adalah ;

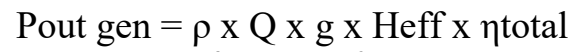
$=1000 \mathrm{~kg} / \mathrm{m}^{3} \times 9.8 \mathrm{~m} / \mathrm{s}^{2} \times 1.2 \mathrm{~m}$ $\mathrm{x} 0.1274 \mathrm{~m}^{3} / \mathrm{s} \times 0.7$ $\sim 1.048$ Watt

$\sim 1.0 \mathrm{~kW}$

(Bustami,2017) :

\section{Pembuatan Bendung}

Bendung dibuat dari campuran batu kali, pasir dan semen. Bendung berfungsi untuk menaikkan/mengontrol tinggi air dalam sungai secara signifikan sehingga memiliki jumlah air yang cukup untuk dialirkan menuju saluran pembawa. Bendung dilengkapi dengan saringan dari jaring kawat untuk menjaga sampah tidak masuk ke saluran pembawa.

\section{Pembuatan saluran pembawa}

Saluran pembawa mengikuti kontur dari sisi bukit untuk menjaga elevasi dari air yang sudah terpisah dari sampah yang akan disalurkan ke penstock. Saluran pembawa merupakan saluran terbuka dengan konstruksi berupa pasangan batu kali, pasir dan semen. Ukuran saluran pembawa panjang 7 meter, lebar 0,4 meter, tinggi $0,4 \mathrm{~m}$ dengan tebal $0,1 \mathrm{~m}$. Gambar 3 menunjukkan rancangan saluran pembawa dan gambar 4 menunjukkan pembuatan saluran pembawa.

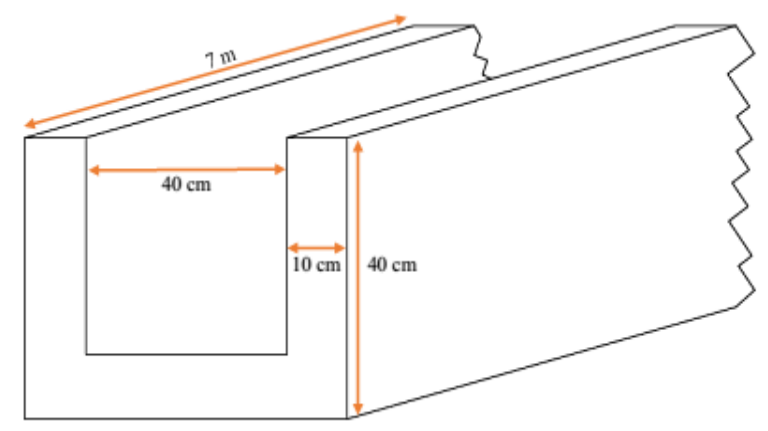

Gambar 3. Rancangan saluran pembawa 


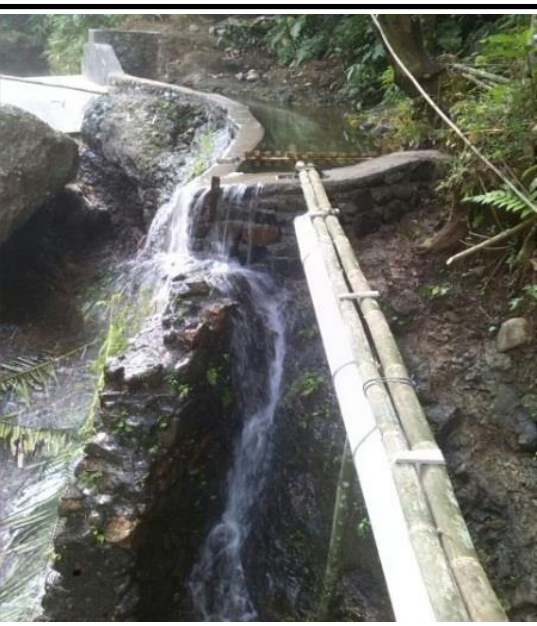

Gambar 4. Pembuatan saluran pembawa

\section{Penstock dan Rumah Pembangkit}

Pipa pesat (penstock) digunakan untuk mengalirkan air untuk menggerakkan turbin yang berasal dari saluran pembawa. Rumah pembangkit digunakan untuk menempatkan generator dan turbin untuk melindungi pengoperasian serta memudahkan perawatannya. Penstock terbuat dari pipa PVC 6 inch. Rumah pembangkit terbuat dari kayu pinus sebagai rangka bangunan dan bambu sebagai rangka atap.

\section{Pembuatan Turbin}

Turbin air berperan untuk mengubah energi air (energi potensial, tekanan dan energi kinetik) menjadi energi mekanik dalam bentuk putaran poros (IMIDAP, 2009). Putaran poros turbin ini akan diubah oleh generator menjadi tenaga listrik. Turbin berbahan plat baja tebal 2,5 $\mathrm{mm}$, diameter luar turbin $95 \mathrm{~cm}$ dan diameter dalam $50 \mathrm{~cm}$ sebagai dudukan runner yang berukuran $25 \mathrm{~cm} \mathrm{x} 23 \mathrm{~cm}$.

\section{Pemasangan turbin-generator}

Generator merupakan alat yang berfungsi untuk mengubah energi mekanik putaran poros menjadi energi energi listrik. Konversi Energi tersebut berlangsung melalui medium medan magnet. Turbin air berperan untuk mengubah energi air (energi potensial, tekanan dan energi kinetik) menjadi energi mekanik dalam bentuk putaran poros. Putaran poros turbin ini akan diubah oleh generator menjadi tenaga listrik.Turbin diletakkan dibawah ujung penstock untuk menerima energ potensial air. Putaran turbin dikopel menggunakan belt sehingga putaran dapat ditransmisikan ke poros generator untuk diubah menjadi energi listrik.

\section{Pembuatan penerangan jalan umum}

Penerangan jalan umum (PJU) dibuat menjadi 14 titik, lebih banyak dibanding rencana hanya 10 titik untuk mengakomodir kebutuhan warga. Panjang jalan yang dapat dilayani PJU ini sekitar $700 \mathrm{~m}$. Kawat SR digunakan dari pembangkit dibawah jalan sekitar 150 meter kemudian ditarik menuju tiang-tiang PJU berbahan kayu petung dan pipa pralon. Kawat SR ditanam dalam tanah untuk mengurangi resiko bahaya dan kerusakan. Dari tiang ke lampu digunakan kawat NYM $2 \times 1,5 \mathrm{~mm}$ menuju ke fitting lampu. Pemasangan dilakukan bersama warga lintas RT.

\section{Transfer pengetahuan}

Selama pelaksanaan pembuatan pembangkit listrik tenaga piko hidro dan pembuatan PJU masyarakat RW III dusun Siwarak tidak hanya RT 02 dan 03 , secara tidak langsung telah teredukasi mengenai pemanfaatan potensi energi lokal untuk memenuhi kebutuhan bersama dan penghematan energi listrik untuk penerangan. Khusus untuk menjamin keberlanjutan operasional pembangkit listrk tenaga piko hidro yang telah dibuat ada 2 orang yang teredukasi dan dapat bertanggung jawab menjaga operasional dan pemeliharaan. Diharapkan potensi energi air di wilayah ini dapat dimanfaatkan lebih maksimal dengan dukungan berbagai instansi termasuk perguruan tinggi, sehingga usaha peningkatan, pemeliharaan dan perbaikan dapat terperhatikan pendanaannya. 
Hari Prasetijo, Widhiatmoko H.P, P. Setyo Nugroho

Transfer Pengetahuan Pembuatan Pembangkit Listrik Tenaga Pikohidro Untuk Penerangan Jalan

\section{SIMPULAN}

Tahapan metode yang dilakukan telah berhasil mencapai tujuan kegiatan yaitu : (1) membuat pembangkit listrik tenaga (PLT) piko hidro kapasitas 1000 watt, (2) membuat penerangan jalan umum menggunakan LED dari sumber PLT piko hidro pada 14 titik dan (3) meningkatkan pengetahuan masyarakat tentang teknologi piko hidro dan penghematan energi listrik untuk penerangan jalan umum.

\section{DAFTAR PUSTAKA}

Akhmad, K., Prasetijo, H., \& Winasis, (2008). Teknologi Energi Terbarukan. Bahan Ajar Program Studi Teknik Elektro Unsoed.

Bustami, A. M., (2017). Rancang Bangun Pembangkit Listrik Pikohidro 1000 VA dengan Memanfaatkan Pembuangan Air Limbah Pada Gedung Pakarti. Artikel, Seminar Nasional Sains dan Teknologi, Fakultas Teknik Universitas Muhammadiyah Jakarta.

ESDM Banyumas, (2004). Executive Summary Rencana Umum Ketenagalistrikan Daerah (RUKD) Kabupaten Banyumas

Faridah, B. U., (2018), Analisis Efisiensi Penggunaan Lampu Light Emitten Diode (LED). Journal of Electrical Technology, 3 (1).

Myson., (2013). Kajian Potensi Arus Sungai Lagan Sebagai Pembangkit Listrik. Jurnal Ilmiah Universitas Batanghari Jambi 13 (4),174-180

Integrated Microhydro Development and Application Program (IMIDAP). (2009). Pedoman Pembangunan PLTMH Jilid 3,4,6,7. Direktorat jenderal listrik dan pemanfaatan energi, Departemen energi dan sumberdaya mineral.

\author{
Kaigai, (2003). Panduan Untuk \\ Pembangunan Listrik Mikro \\ Hidro. Japan International \\ Coorporation Agency (JICA).
}

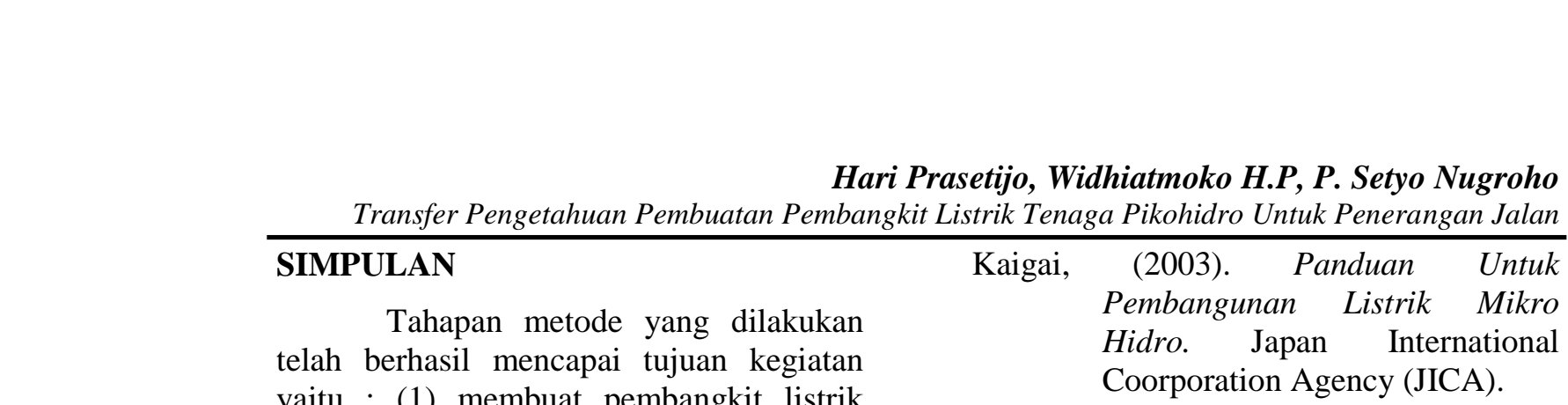

